\title{
Cyproterone acetate or spironolactone in lowering testosterone concentrations for transgender individuals receiving oestradiol therapy
}

\author{
Lachlan Angus ${ }^{1}$, Shalem Leemaqz ${ }^{2}$, Olivia Ooi ${ }^{1}$, Pauline Cundill ${ }^{3}$, Nicholas Silberstein ${ }^{3}$, Peter Locke ${ }^{3}$, Jeffrey D Zajac ${ }^{1}$ \\ and Ada S Cheung ${ }^{1}$
}

'Department of Medicine (Austin Health), The University of Melbourne, Heidelberg, Victoria, Australia

${ }^{2}$ Robinson Research Institute, Adelaide Medical School, The University of Adelaide, Adelaide, South Australia

${ }^{3}$ Equinox Gender Diverse Clinic, Thorne Harbour Health, Fitzroy, Victoria, Australia

Correspondence should be addressed to A S Cheung: adac@unimelb.edu.au

\begin{abstract}
Background: Oestradiol with or without an anti-androgen (cyproterone acetate or spironolactone) is commonly prescribed in transfeminine individuals who have not had orchidectomy; however, there is no evidence to guide optimal treatment choice.

Objective: We aimed to compare add-on cyproterone acetate versus spironolactone in lowering endogenous testosterone concentrations in transfeminine individuals.

Design: Retrospective cross-sectional study.

Methods: We analysed 114 transfeminine individuals who had been on oestradiol therapy for $>6$ months in two gender clinics in Melbourne, Australia. Total testosterone concentrations were compared between three groups; oestradiol alone $(n=21)$, oestradiol plus cyproterone acetate $(n=21)$ and oestradiol plus spironolactone $(n=38)$. Secondary outcomes included serum oestradiol concentration, oestradiol valerate dose, blood pressure, serum potassium, urea and creatinine.

Results: Median age was 27.0 years (22.5-45.1) and median duration of hormone therapy was 1.5 years $(0.9-2.6)$, which was not different between groups. On univariate analysis, the cyproterone group had significantly lower total testosterone concentrations $(0.8 \mathrm{nmol} / \mathrm{L}(0.6-1.20))$ compared with the spironolactone group $(2.0 \mathrm{nmol} / \mathrm{L}(0.9-9.4)$, $P=0.037)$ and oestradiol alone group $(10.5 \mathrm{nmol} / \mathrm{L}(4.9-17.2), P<0.001)$, which remained significant $(P=0.005)$ after adjustments for oestradiol concentration, dose and age. Serum urea was higher in the spironolactone group compared with the cyproterone group. No differences were observed in total daily oestradiol dose, blood pressure, serum oestradiol, potassium or creatinine.

Conclusions: The cyproterone group achieved serum total testosterone concentrations in the female reference range. As spironolactone may cause feminisation without inhibition of steroidogenesis, it is unclear which anti-androgen is more effective at feminisation. Further prospective studies are required.
\end{abstract}




\section{Introduction}

Rapid rises in demand for transgender health services have been observed worldwide $(1,2)$. Birth-assigned males who wish to transition to female (hereafter termed transfeminine individuals) are typically treated with oestradiol as feminising gender-affirming hormone therapy (3). Goals of therapy are generally to increase serum oestradiol concentrations and lower serum total testosterone concentrations to achieve sex steroid concentrations in the female reference range. Over 3-24 months, this leads to feminine physical characteristics including softening of skin, a decrease in facial and body hair growth, changes in body fat and muscle distribution, as well as breast development (4). Oestradiol improves psychological functioning in transfeminine individuals (5); however, oestradiol alone is usually insufficient to lower serum total testosterone concentrations from a male to a female reference range. Oestradiol suppresses gonadotropin-releasing hormone (GnRH) via negative feedback, in turn partially lowering testosterone. However, as the majority of individuals ( $82 \%$ in our clinics (1)) do not undergo genital reassignment surgery to remove the testes, which are responsible for $>95 \%$ of testosterone production, most individuals will require treatment with an additional anti-androgen drug. Anti-androgens such as cyproterone acetate or spironolactone are commonly added to oestradiol, lowering or blocking the effects of testosterone to aid development of feminising physical characteristics.

In transfeminine individuals wishing to inhibit androgenic physical characteristics, choice of antiandrogen agent is a common clinical scenario faced by patients and treating clinicians alike. Whilst both antiandrogen agents, cyproterone acetate and spironolactone, have been shown to lower serum testosterone concentrations if added to oestradiol treatment, there is little evidence to guide the superiority of one antiandrogen over another (6). Both cyproterone acetate and spironolactone have peripheral anti-androgen effects, but cyproterone acetate additionally has progestogenic actions which may be more effective in suppressing GnRH and in turn, testosterone concentrations.

As there are no data to support one drug over the other, prescription of anti-androgens is often a random choice with over $90 \%$ of experienced prescribers of genderaffirming hormone therapy using both agents with no rationale for one or the other (7). Yet, cyproterone may be associated with adverse effects such as depression, and spironolactone may be associated with excess diuresis, electrolyte imbalance and hypotension, which impact upon treatment choice.

In this retrospective audit of individuals on established feminising hormone therapy, we aimed to compare the serum total testosterone concentrations of individuals on established treatment with oestradiol alone, oestradiol with additional cyproterone acetate and oestradiol with additional spironolactone. We hypothesised that in transfeminine individuals on oestradiol therapy, a greater proportion of individuals receiving additional cyproterone acetate would have total testosterone concentrations $<2 \mathrm{nmol} / \mathrm{L}$ (the female reference range in our laboratory) compared to those receiving additional spironolactone or oestradiol alone.

\section{Methods}

A retrospective audit of de-identified electronic medical records was performed of new consultations for gender dysphoria across two gender clinics in Melbourne, Australia: (a) Equinox Gender Diverse Clinic, an adult primary care general practice clinic with a focus on transgender health and (b) an adult endocrine specialist clinic. New consecutive consultations between 1 January 2011 and 31 December 2016 were analysed. As the primary care clinic commenced on 22 February 2016, data were analysed for the first 12 months of operation until 22 February 2017. The study was approved by the Austin Health Human Research Ethics Committee (LNR/17/Austin/102) and the nature of the study did not necessitate informed consent.

Clinical characteristics of the audit have been previously published (1). This cross-sectional analysis included transfeminine individuals newly presenting to the clinics who had been on established feminising hormone therapy with oestradiol for at least 6 months and had fasting serum sex steroid results available within 1 month of their initial consultation. We excluded individuals who were expected to have castrate testosterone concentrations (previous orchidectomy or concurrent GnRH agonist therapy) and individuals on ethinyl oestradiol treatment as this was not measurable on oestradiol immunoassay.

The primary outcome of interest was serum fasting total testosterone concentration by treatment group: (a) oestradiol alone, (b) oestradiol plus additional cyproterone acetate and (c) oestradiol plus additional spironolactone. Other parameters of interest included serum oestradiol concentration, potassium, urea and creatinine, 
haemoglobin, liver function (alanine transaminase (ALT)), oestradiol valerate dose and blood pressure.

As data were obtained retrospectively, sex steroid concentrations, biochemistry and haemoglobin were performed using immunoassay available as standard care for clinical decision-making. Multiple National Association of Testing Authorities (NATA, the national accreditation body for Australia) accredited laboratories available locally were used.

Statistical analyses were performed using R (v3.5.1; $\mathrm{R}$ foundation for statistical computing). Median (IQR) are reported and differences between were tested using Kruskal-Wallis test followed by Nemenyi post hoc comparisons. A linear mixed model was also fitted to compare total testosterone concentrations between the three treatment groups, adjusting for corresponding oestradiol concentrations, doses and age. Total testosterone concentrations were log-transformed to approximate normality, and results were back-transformed to show the geometric means. Differences between recruitment centres were accounted for as a random effect. Post hoc pairwise comparisons between the three groups with Tukey's adjustment was also performed. For all analyses, the significance level was set at 5\%.

\section{Results}

Of 540 individuals in our clinical audit, 136 (36\%) were birth-assigned males (transfeminine individuals). 122 were taking oestradiol but only 114 individuals had received feminising hormone therapy with oestradiol for $>6$ months. After excluding individuals who had previous orchidectomy $(n=28)$, concurrent GnRH agonist therapy $(n=1)$ and ethinyl oestradiol $(n=4), 80$ individuals had data available for analysis.

Of 80 individuals on established oestradiol therapy for $>6$ months, 21 were on oestradiol alone (oestradiol alone group), 21 were receiving oestradiol plus additional cyproterone acetate (cyproterone group) and 38 were receiving oestradiol plus additional spironolactone (spironolactone group).

There was no significant difference between the age and duration of hormonal therapy between the three groups. The median age was 27 years (22-45) and median duration of hormonal therapy was 1.5 years (0.9-2.6). Oral oestradiol valerate was the most common formulation used in $88.3 \%$ of individuals and the remainder used transdermal oestradiol (11.7\%) which are the two most common formulations available on the Australian
Pharmaceutical Benefits Scheme. The median doses used were oestradiol valerate $6 \mathrm{mg}(4,6)$, cyproterone acetate $50 \mathrm{mg}(25,50)$ and spironolactone $100 \mathrm{mg}(87.5-200)$.

The serum total testosterone concentrations for the three groups are shown in Fig. 1. The median serum total testosterone concentrations were $10.5 \mathrm{nmol} / \mathrm{L}$ (4.9-17.2) in the oestradiol alone group, $0.8 \mathrm{nmol} / \mathrm{L}$ $(0.6-1.2)$ in the cyproterone group and $2.0 \mathrm{nmol} / \mathrm{L}$ (0.9-9.4) in the spironolactone group. On univariate analysis, the cyproterone group had significantly lower serum total testosterone concentrations than the spironolactone group and the oestradiol-alone group. After adjustment for oestradiol concentration, oestradiol dose, spironolactone dose, cyproterone dose and age (Fig. 2), this remained significantly different $(P=0.005)$. Findings were unchanged after excluding those on transdermal oestradiol. 90\% of the cyproterone group and $40 \%$ of the spironolactone group had total testosterone concentrations $<2 \mathrm{nmol} / \mathrm{L}$.

Serum urea was higher in the spironolactone group than the cyproterone group but all results remained in the normal reference range (3-9.2 $\mathrm{mmol} / \mathrm{L})$ for the assay. No differences were observed in total daily oestradiol valerate dose, oestradiol concentration achieved, body mass index, blood pressure, haemoglobin, creatinine or ALT (Table 1).

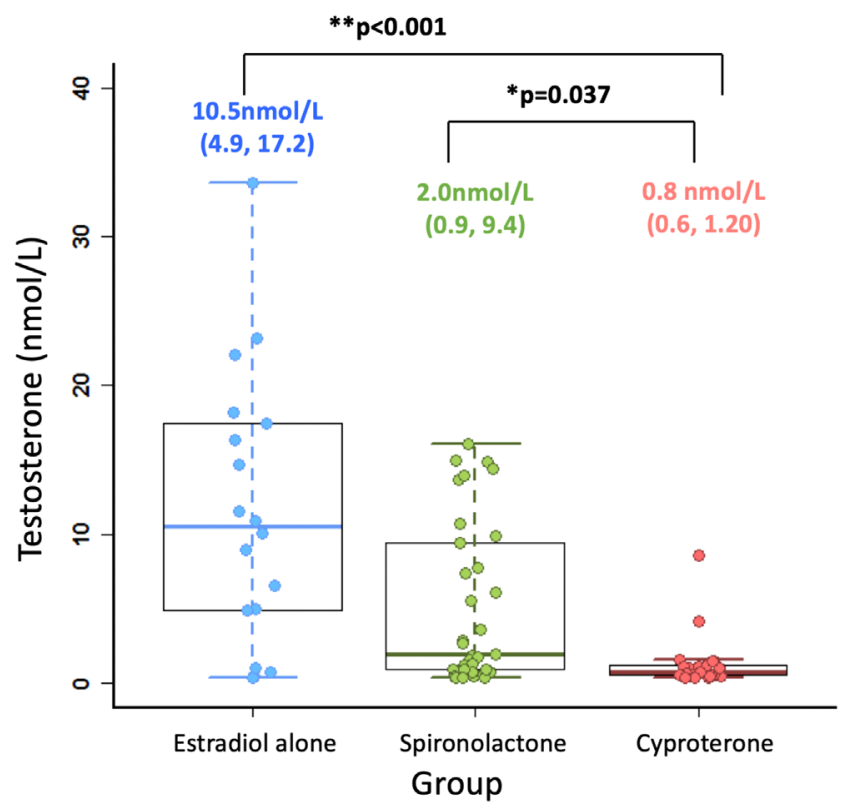

Figure 1

Box plots demonstrating median, interquartile range and range for total testosterone (nmol/L) for three groups. The median (IQR) is printed above and $P$ values represent comparison with cyproterone acetate group.

This work is licensed under a Creative Commons Attribution-NonCommercial-NoDerivatives 4.0 Internationab kicense.ifica, com at $04 / 26 / 2023 \quad 12: 05: 25 \mathrm{PM}$ 


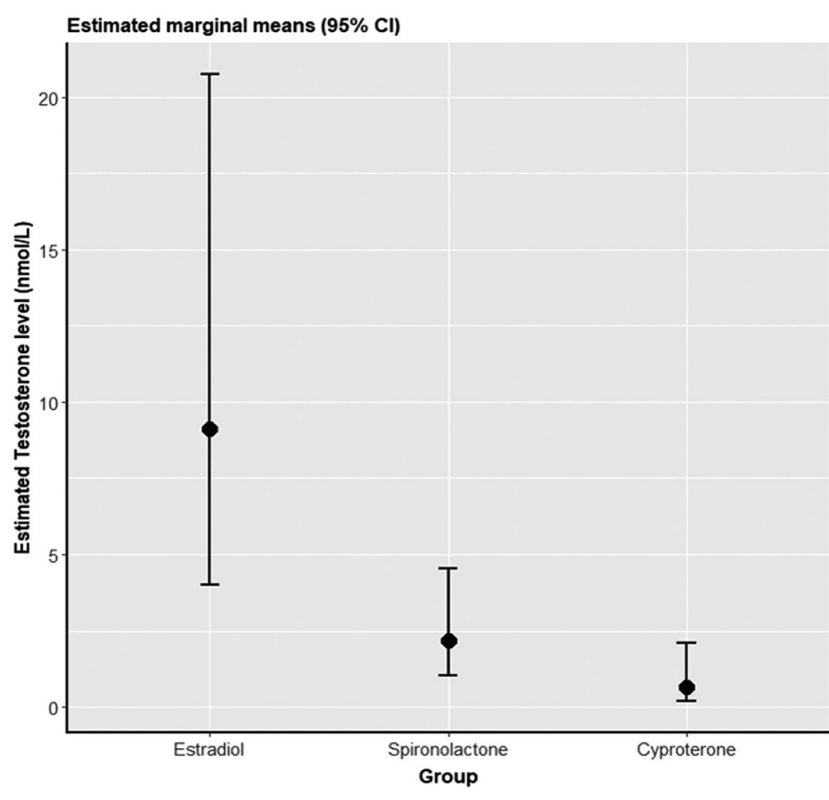

Figure 2

Estimated marginal means $(95 \% \mathrm{Cl})$ for the three groups from a linear mixed model adjusting for oestradiol concentration, oestradiol dose, spironolactone dose, cyproterone dose and age, with recruitment centre as random effect. Total testosterone concentrations were backtransformed to show the geometric mean of each group.

\section{Discussion}

In this retrospective cross-sectional analysis, transfeminine individuals undergoing feminising hormone therapy with oestradiol achieved the lowest total testosterone concentrations with additional cyproterone acetate when compared to additional spironolactone or oestradiol alone. Serum urea concentrations were higher in the spironolactone group than the cyproterone group and oestradiol alone group but no differences were observed in serum creatinine. No differences were observed in the serum oestradiol concentration achieved, total oestradiol valerate dose required, blood pressure or liver function between the three groups.

Supporting our findings, a recently published US retrospective audit of 98 transfeminine individuals found only a quarter of those on spironolactone achieved total testosterone concentrations in the female reference range (8). Notably, although cyproterone has been used internationally for many years, it is not available in the US due to rare case reports of hepatotoxicity in men receiving high doses for prostate cancer (9). Reasons for the variable effects of spironolactone and cyproterone on serum testosterone concentrations may well be related to differing mechanisms of action.

Spironolactone is a mineralocorticoid receptor antagonist and is anti-androgenic in four ways. First, it is a peripheral androgen receptor partial antagonist $(\mathrm{IC} 50=77 \mathrm{nmol} / \mathrm{L})$ (10). The IC50, which is the concentration of an inhibitor where the binding is reduced by half, is higher than that of cyproterone acetate, reflecting less potency. Second, spironolactone is a weak inhibitor of $17 \alpha$-hydroxylase and 17,20 -lyase (enzymes in the testosterone biosynthetic pathway) which lowers testosterone to a small degree. Third, it has weak progestogenic activity with a very low half-maximal potency (10); and fourth, it has oestrogenic activity expected to suppress GnRH and gonadotropins at the hypothalamus and pituitary (10). However, even at high doses, small pharmacokinetic studies in healthy males show no significant reduction in serum testosterone, despite a transient rise in FSH and LH in the first 2 days of administration $(11,12)$. Interestingly, administration of the main metabolite of spironolactone, canrenone, appears to decrease testosterone by $50-60 \%$ within hours in healthy men (13) and in conjunction with oestradiol, spironolactone decreases testosterone (14).

Table 1 Comparison of secondary outcomes by treatment group.

\begin{tabular}{l} 
Parameter \\
\hline Urea $(\mathrm{mmol} / \mathrm{L})$ \\
Creatinine $(\mu \mathrm{mol} / \mathrm{L})$ \\
Oestradiol valerate dose $(\mathrm{mg})$ \\
Oestradiol concentration $(\mathrm{pmol} / \mathrm{L})$ \\
BMI $\left(\mathrm{kg} / \mathrm{m}^{2}\right)$ \\
Systolic BP $(\mathrm{mmHg})$ \\
Diastolic BP $(\mathrm{mmHg})$ \\
Haemoglobin $(\mathrm{g} / \mathrm{L})$ \\
ALT $(\mathrm{U} / \mathrm{L})$
\end{tabular}

\begin{tabular}{c}
\hline \\
\hline Oestradiol alone $(N=21)$ \\
\hline $4.9(4.2-5.8)$ \\
$78(72-96)$ \\
$6(4-6)$ \\
$256(119-408)$ \\
$27.2(23.1-31.9)$ \\
$125(121-131)$ \\
$80(75-81)$ \\
$147(143-159)$ \\
$21(15-28)$ \\
\hline
\end{tabular}

Group $\boldsymbol{n}=\mathbf{8 0}$ (total)
Cyproterone $(N=21)$
$4.2(3.6-5.1)$
$72(63-75)$
$5(4-6)$
$279(149-334)$
$24.5(23.4-30.3)$
$123(118-136)$
$85(80-90)$
$148(143-151)$
$23(15-29)$

\begin{tabular}{c} 
Spironolactone $(N=38)$ \\
\hline $5.0(4.3-6.0)$ \\
$77(69-85)$ \\
$6(4-6)$ \\
$279(233-384)$ \\
$24.7(23.5-31.0)$ \\
$125(120-136)$ \\
$80(75-82)$ \\
$146(138-158)$ \\
$19(14-24)$
\end{tabular}

\begin{tabular}{c} 
P value \\
\hline 0.035 \\
0.069 \\
0.601 \\
0.795 \\
0.989 \\
0.941 \\
0.056 \\
0.880 \\
0.630
\end{tabular}

Median (IQR) are presented. $P$ values refer to overall difference between the groups and are obtained from the Kruskal-Wallis test as a non-parametric alternative to $t$-test. 
Cyproterone acetate is a steroidal anti-androgen and works in two ways. First, it is a potent peripheral androgen receptor competitive antagonist (IC50 $=7.1 \mathrm{nmol} / \mathrm{L}$ ) acting at peripheral sites (i.e. skin, hair, body fat, muscle) to decrease the effect of testosterone (15). Second, it activates the progesterone receptor which, similar to oestradiol treatment, causes further negative feedback to suppress $\mathrm{GnRH}$ and gonadotropins at the hypothalamus and pituitary respectively to lower testosterone production (16, 17). As spironolactone may potentially cause feminisation by direct antagonism of the androgen receptor without reduction of serum testosterone, it is unclear which antiandrogen is more effective at feminisation and prospective studies are required.

Serum urea was noted to be higher in the spironolactone group compared to the cyproterone group and oestradiol alone group. This is likely related to the diuretic effect of spironolactone, however reassuringly despite a reasonably high median dose of spironolactone (100 mg daily), serum urea in the spironolactone group remained within normal reference range and no changes between groups were observed in haemoglobin, serum creatinine or blood pressure.

Serum oestradiol concentrations achieved were no different between the groups and were generally between 250 and $350 \mathrm{pmol} / \mathrm{L}$ on a relatively high median dose of oral oestradiol valerate of $6 \mathrm{mg}$ daily. This dose is certainly higher than that used in the European Network for Investigation of Gender Incongruence (4mg) (18), yet oestradiol concentrations achieved are lower than the recommended concentrations (367-734 pmol/L) in international guidelines (3). Notably, no studies have examined what oestradiol concentrations are optimal in transfeminine individuals and guideline recommendations are based on predominantly expert opinion. Moreover, there are no prospective studies examining the effectiveness of different formulations and doses of oestradiol therapy for feminisation. Further research is required to optimally guide clinical care.

There are a number of limitations to this retrospective cross-sectional analysis inherent in the design and small numbers of individuals. Individuals were not randomised to the groups which may confound results and we did not have details regarding rationale for choice of antiandrogen drug. Importantly, we cannot account for factors such as clinician preference or whether patients taking oestradiol alone or spironolactone may have accepted or desired higher testosterone levels. We also did not have data regarding feminising physical characteristics and due to differing mechanisms of action of cyproterone acetate and spironolactone, serum total testosterone concentrations alone may not necessarily represent effectiveness of feminisation. Due to the cross-sectional nature of the study, adverse effects of medications were not able to be determined. Total serum testosterone concentrations were measured by immunoassay, which lacks precision at low serum testosterone concentrations (as opposed to more sensitive liquid chromatography-tandem mass spectrometry (LC-MS)), as sex steroid concentrations were performed as part of standard care for clinical decision-making. As a result, sex steroid concentrations were performed at various NATA-accredited laboratories. Nonetheless, this is the first comparison of the effect of cyproterone acetate and spironolactone on total testosterone concentrations and given the lack of research in the transgender field, our findings may have implications for clinical decisionmaking for transfeminine individuals who have not undergone orchidectomy.

\section{Conclusions}

As gender-affirming hormone therapy is typically given lifelong and commenced at a young age, selecting the optimal anti-androgen to suppress serum testosterone and hence aid feminisation is a highly important decision for patients and clinicians alike. Cyproterone is highly effective at lowering endogenous total testosterone concentrations in transfeminine individuals undergoing feminising hormone therapy. Due to differing mechanisms of action, differences in anti-androgenic or feminising effects of cyproterone and spironolactone are unclear. Further prospective research studies are required.

\section{Declaration of interest}

The authors declare that there is no conflict of interest that could be perceived as prejudicing the impartiality of the research reported.

\section{Funding}

Ada Cheung is supported by an Australian Government National Health and Medical Research Council Early Career Fellowship (\#1143333) and receives research support from the Viertel Charitable Foundation Clinical Investigator Award, Endocrine Society of Australia Postdoctoral Award and the Royal Australasian College of Physicians Vincent Fairfax Family Foundation.

\section{References}

1 Cheung AS, Ooi O, Leemaqz S, Cundill P, Silberstein N, Bretherton I, Thrower E, Locke P, Grossmann M \& Zajac JD. Sociodemographic 
and clinical characteristics of transgender adults in Australia. Transgender Health 20183 229-238. (https://doi.org/10.1089/ $\operatorname{trgh} .2018 .0019)$

2 Delahunt JW, Denison HJ, Sim DA, Bullock JJ \& Krebs JD. Increasing rates of people identifying as transgender presenting to Endocrine Services in the Wellington region. New Zealand Medical Journal 2018 $13133-42$.

3 Hembree WC, Cohen-Kettenis PT, Gooren L, Hannema SE, Meyer WJ, Murad MH, Rosenthal SM, Safer JD, Tangpricha V \& T'Sjoen GG. Endocrine treatment of gender-dysphoric/gender-incongruent persons: an Endocrine Society* clinical practice guideline. Journal of Clinical Endocrinology and Metabolism 2017102 3869-3903. (https:// doi.org/10.1210/jc.2017-01658)

4 Klaver M, de Blok CJM, Wiepjes CM, Nota NM, Dekker MJHJ, de Mutsert R, Schreiner T, Fisher AD, T'Sjoen G \& den Heijer M. Changes in regional body fat, lean body mass and body shape in trans persons using cross-sex hormonal therapy: results from a multicenter prospective study. European Journal of Endocrinology 2018 178 163-171. (https://doi.org/10.1530/EJE-17-0496)

5 White Hughto JM \& Reisner SL. A systematic review of the effects of hormone therapy on psychological functioning and quality of life in transgender individuals. Transgender Health $2016121-31$. (https:// doi.org/10.1089/trgh.2015.0008)

6 Tangpricha V \& den Heijer M. Oestrogen and anti-androgen therapy for transgender women. Lancet: Diabetes and Endocrinology 20175 291-300. (https://doi.org/10.1016/S2213-8587(16)30319-9)

7 Bretherton I, Thrower E, Grossmann M, Zajac JD \& Cheung AS. Cross-sex hormone therapy in Australia: the prescription patterns of clinicians experienced in adult transgender healthcare. Internal Medicine Journal 201949 182-188. (https://doi.org/10.1111/imj.14035)

8 Liang JJ, Jolly D, Chan KJ \& Safer JD. Testosterone levels achieved by medically treated transgender women in a United States endocrinology clinic cohort. Endocrine Practice 201824 135-142. (https://doi.org/10.4158/EP-2017-0116)

9 Savidou I, Deutsch M, Soultati AS, Koudouras D, Kafiri G \& Dourakis SP. Hepatotoxicity induced by cyproterone acetate: a report of three cases. World Journal of Gastroenterology $2006 \mathbf{1 2} 7551-7555$. (https://doi.org/10.3748/wjg.v12.i46.7551)

10 Fagart J, Hillisch A, Huyet J, Barfacker L, Fay M, Pleiss U, Pook E, Schafer S, Rafestin-Oblin ME \& Kolkhof P. A new mode of mineralocorticoid receptor antagonism by a potent and selective nonsteroidal molecule. Journal of Biological Chemistry 2010285 29932-29940. (https://doi.org/10.1074/jbc. M110.131342)

11 Stripp B, Taylor AA, Bartter FC, Gillette JR, Loriaux DL, Easley R \& Menard RH. Effect of spironolactone on sex hormones in man. Journal of Clinical Endocrinology and Metabolism 197541 777-781. (https://doi.org/10.1210/jcem-41-4-777)

12 Miyatake A, Noma K, Nakao K, Morimoto Y \& Yamamura Y. Increased serum oestrone and oestradiol following spironolactone administration in hypertensive men. Clinical Endocrinology 19789 523-533. (https://doi.org/10.1111/j.1365-2265.1978.tb01510.x)

13 Erbler HC. Suppression by the spironolactone metabolite canrenone of plasma testosterone in man. Naunyn-Schmiedeberg's Archives of Pharmacology 1974285 403-406. (https://doi.org/10.1007/ BF00501468)

14 Prior JC, Vigna YM \& Watson D. Spironolactone with physiological female steroids for presurgical therapy of male-to-female transsexualism. Archives of Sexual Behavior 198918 49-57. (https:// doi.org/10.1007/BF01579291)

15 Sonneveld E, Jansen HJ, Riteco JA, Brouwer A \& van der Burg B. Development of androgen- and estrogen-responsive bioassays, members of a panel of human cell line-based highly selective steroidresponsive bioassays. Toxicological Sciences 200583 136-148. (https:// doi.org/10.1093/toxsci/kfi005)

16 Gava G, Cerpolini S, Martelli V, Battista G, Seracchioli R \& Meriggiola MC. Cyproterone acetate vs leuprolide acetate in combination with transdermal oestradiol in transwomen: a comparison of safety and effectiveness. Clinical Endocrinology 2016 85 239-246. (https://doi.org/10.1111/cen.13050)

17 Toorians AW, Thomassen MC, Zweegman S, Magdeleyns EJ, Tans G, Gooren LJ \& Rosing J. Venous thrombosis and changes of hemostatic variables during cross-sex hormone treatment in transsexual people. Journal of Clinical Endocrinology and Metabolism 200388 5723-5729. (https://doi.org/10.1210/jc.2003-030520)

18 Dekker MJ, Wierckx K, Van Caenegem E, Klaver M, Kreukels BP, Elaut E, Fisher AD, van Trotsenburg MA, Schreiner T, den Heijer M, et al. A European Network for the Investigation of gender incongruence: endocrine part. Journal of Sexual Medicine $2016 \mathbf{1 3}$ 994-999. (https://doi.org/10.1016/j.jsxm.2016.03.371)

Received in final form 4 June 2019

Accepted 11 June 2019

Accepted Preprint published online 11 June 2019 https://ec.bioscientifica.com https://doi.org/10.1530/EC-19-0272 (c) 2019 The authors Published by Bioscientifica Ltd
This work is licensed under a Creative Commons Attribution-NonCommercial-NoDerivatives 4.0 Internationad bicense.ifica.com at 04/26/2023 12:05:25PM 